\title{
Foreword-special issue on CICBA-18
}

\author{
Bharat Bhushan ${ }^{1}$
}

Published online: 15 October 2021

(C) The Author(s), under exclusive licence to Springer-Verlag GmbH Germany, part of Springer Nature 2021

This special issue consists of selected papers presented at the Second International Conference on Computational Intelligence, Communications, and Business Analytics (CICBA-2018). The conference was organized by the Kalyani Government Engineering College, Kalyani, West Bengal, India. The conference covered all aspects of Computational Intelligence, Communications and Business Analytics in computer science and engineering, general science, educational research and management science. The conference provided a platform to the participants to share their views and ideas on latest technological developments.

Authors of selected papers from the conference were invited to submit full length papers for possible inclusion in this special issue of Microsystem Technologies (MST).
The papers were on cloudlets-based resource management for IoT, FPGA implementation of software defined radio, Energy efficient routing, load balancing in routing, submicron high electron mobility transistor and low power full adder design. All papers were refereed according to the rigorous journal standards. The review process was coordinated by guest editor, Prof. Jyotsna Kumar Mandal. Six papers were accepted for publication in this issue.

We hope that readers find the papers in the issue to be informative.

Prof. Bharat Bhushan

Co-Editor in Chief, MST

October 2021

Publisher's Note Springer Nature remains neutral with regard to jurisdictional claims in published maps and institutional affiliations.

Bharat Bhushan

bhushan100@outlook.com

1 San Jose, CA, USA 